ARAGÃO, A., «La protección legal de las reservas de la biosfera en Portugal», REDUR I3, diciembre 20I5, págs. $2 \mathrm{I}-37$.

ISSN I695-078X

\title{
LA PROTECCIÓN LEGAL DE LAS RESERVAS DE BIOSFERA EN PORTUGAL
}

\author{
Alexandra ARAGÃo \\ ProfESSORA DA FACUlDAdE DE DiREITO E INVESTIGADORA DO INSTITUTO JURÍDiCO \\ UNIVERSIDADE DE COIMBRA
}

SUMARIO: I. O programa o Homem e a biosfera, da Unesco. II. As reservas portuguesas. II.I. Reservas transfronteiriças. II.2. Reservas insulares. III. Regime de proteção aplicável. III.I. Regime geral da conservação da natureza e biodiversidade. III.2. Regime de conservação da natureza e biodiversidade nos açores. III.3. Relação entre as reservas de biosfera e a rede nacional de áreas protegida. IV. Descrição da organização institucional. V. Conclusão.

RESUMEN: Treinta años después de haber propuesto la primera reserva de biosfera, Portugal está ahora determinado a llevar en serio, por primera vez, la etiqueta Unesco. Con tres reservas de biosfera en territorio continental y seis en islas el Gobierno finalmente ha comprendido la importancia para la población, y para la biodiversidad, del compromiso con la promoción de estilos de vida sostenibles, a fin de reconciliar la protección ambiental con el bienestar humano. Las reservas de biosfera son ahora consideradas como laboratorios de desarrollo sostenible, en armonía con la naturaleza. Las ventajas económicas, sociales y ambientales de esta visión resultan bastante evidentes.

Palabras Clave: Reservas de biosfera, conservación de la naturaleza, ventajas turísticas, etiqueta Unesco.

ABSTRACT: More than 30 years after having proposed the first biosphere reserves, Portugal e now determined to take the Unesco label seriously, for the first time. With 3 biosphere reserves in the continental territory, and 6 in the islands, the government final understood the importance both for the local population and for biodiversity conservation, of engaging in the promotion of sustainable development lifestyles, to reconcile man and the biosphere and to support sustainable living in harmony with nature. The advantages of this approach are quite obvious.

KEYWORDS: Biosphere reserves, nature conservation, touristic uses, Unesco label.

\footnotetext{
${ }^{\mathrm{I}}$ Projeto: Crise, sustainabilidade e cidadania UID/DIR/04643/20I3. Este trabajo forma parte de un estudio más amplio que, denominado «Revisión de la legislación iberoamericana en relación con las reservas de la biosfera (I): Aproximación metodológica» y financiado por el Organismo Autónomo Parques Nacionales, ha sido coordinado desde la Universidad de La Rioja por René Javier Santamaría Arinas, Profesor Titular de Derecho Administrativo y miembro del Consejo Científico del Comité Español del Programa Man and Biosphere de la UNESCO.
} 


\section{O programa o Homem e a Biosfera, da Unesco}

Criado em I97I, o programa o Homem e a Biosfera, da Unesco visa a criação de uma rede mundial de reservas de biosfera. Em linha com os Objetivos de Desenvolvimento do Milénio, os fins gerais das reservas de biosfera são a integração harmoniosa das pessoas e da natureza para o desenvolvimento sustentável por meio do diálogo participativo, com respeito pelos valores culturais, mas desenvolvendo a capacidade, por parte da sociedade, de lidar com a mudança.

- Mais especificamente, as finalidades do programa o Homem e a Biosfera são:

- Identificar e avaliar as mudanças na biosfera, resultantes de atividades humanas e naturais, e os efeitos dessas mudanças sobre o homem e o ambiente, em particular no contexto das alterações climáticas;

- Estudar e comparar as inter-relações dinâmicas entre ecossistemas naturais e quase naturais por um lado, e os processos sócio-económicos por outro, em particular no contexto de perda acelerada da diversidade biológica e cultural, com consequências inesperadas que afetam a capacidade de os ecossistemas continuarem a fornecer serviços críticos para o bem-estar humano;

- Assegurar o bem-estar humano básico e um ambiente saudável, no contexto da urbanização e consumo de energia acelerados, como indutores de mudanças ambientais;

- Promover o intercâmbio e a transferência de conhecimento sobre os problemas e soluções ambientais, e fomentar a educação ambiental para o desenvolvimento sustentável ${ }^{2}$.

Atualmente, a rede mundial de reservas de biosfera é composta por 63I sítios da biosfera em iıg países, incluindo I4 locais transfronteiriços, dois dos quais na Península Ibérica.

Em Portugal, o surgimento das reservas de biosfera tem sido lento e a regulamentação tem sido esparsa e dependente dos regimes legais associados a outros estatutos jurídicos.

\section{As reservas portuguesas}

Em Portugal existem atualmente oito reservas de biosfera.

A primeira reserva, do Paul de Boquilobo, ao ser aprovada em ig8I, enquadra-se na primeira geração de reservas, que incluem aquelas que foram criadas durante a primeira década do programa o Homem e a Biosfera, até à aprovação do primeiro plano de ação que, em I984, definiu uma primeira estratégia para a implementação de uma rede mundial de reservas de biosfera. Em 2014 foi apresentado ao Comité Man and the Biosphere (Comité $\mathrm{MaB})$ da Unesco o primeiro relatório de revisão periódica da classificação do Paul de Boquilobo.

\footnotetext{
${ }^{2}$ Para mais informações consultar http://www.unesco.org/new/en/natural-sciences/environment/ecological-sciences/man-and-biosphereprogramme/about-mab/.
} 
Segue-se o segundo plano de ação e a Estratégia de Sevilha, em I995, e em Portugal continua a não haver novidades. Só em 2007 , vinte e seis anos depois da primeira reserva, foram criadas mais duas - a da Graciosa e a do Corvo. A partir daqui o movimento parece ter ganho algum impulso e a criação de reservas sucede-se com uma periodicidade bianual.

Em 2009 é proposta e aceite a criação de mais duas reservas portuguesas, depois de em Madrid, ter sido aprovado o terceiro plano de ação e respetiva estratégia. São as reservas das Flores e Gerês-Xurês, sendo esta a primeira reserva transfronteiriça ibérica. Em 20II, surgem ainda mais duas - a das Berlengas e a de Santana, na Madeira.

Por fim, em 2015, foi aprovada a segunda reserva transfronteiriça ibérica - a da Meseta Ibérica, uma das maiores da Europa, com II32606 ha.

Em curso está a preparação de mais uma candidatura, a da Fajã de São Jorge, nos Açores ${ }^{3}$.

\section{II.I. Reservas transfronteiriças}

A criação de reservas transfronteiriças decorre da opção de intensificar a cooperação internacional, aprofundando as relações luso-espanholas em matéria de conservação da natureza e da biodiversidade, constante da Estratégia Nacional da Conservação da Natureza e da Biodiversidade de 2009. Deste modo, a natureza e a biodiversidade são assuntos recorrentes na agenda dos Ministros do Ambiente no âmbito das Cimeiras LusoEspanholas. Mesmo antes da aprovação da reserva de biosfera Gerês-Xurês já existia um acordo transfronteiriço e um projeto INTERREG (com a Xunta da Galicia e com as vertentes de monitorização e gestão da biodiversidade e visitação), no âmbito do qual foi preparada a candidatura desse Parque a reserva da bioesfera pela Unesco.

\section{II.2. Reservas insulares}

Um fenómeno digno de nota em Portugal é a concentração das reservas de biosfera em zonas insulares. Das nove reservas (oito já aprovadas e uma prevista, em preparação), apenas três se situam em território continental, sendo as restantes insulares: uma na ilha costeira da Berlenga, uma na ilha oceânica da Madeira e quatro no arquipélago oceânico dos Açores ${ }^{4}$.

Nas Orientações de Médio Prazo adotadas em 27 de maio de 2013, após aprovação pela Assembleia Legislativa Regional dos Açores, afirmam claramente que «as ilhas dos Açores são reconhecidas pelo elevado nível de qualidade ambiental e pelo potencial dos seus recursos naturais. A criação de condições para a preservação dos recursos naturais é um desígnio coletivo, uma aposta num desenvolvimento equilibrado e num crescimento futuro

\footnotetext{
${ }^{3}$ A Assembleia Legislativa Regional dos Açores manifestou a intenção política de fazer as diligências necessárias para promover a Fajã de São Jorge - que já goza do estatuto de Geosítio integrado no geoparque dos Açores - não só a reserva de biosfera mas também a património mundial Unesco (Resolução da Assembleia Legislativa da Região Autónoma dos Açores I2/20I5/A, de 20 de março que Recomenda ao Governo Regional dos Açores que elabore, em estreita colaboração com os municípios, o Plano Integrado de Desenvolvimento das Fajãs da ilha de São Jorge).

${ }^{4}$ A vontade política de candidatar parcelas do território insular ao reconhecimento pela Unesco como reservas de biosfera é uma intenção formalmente manifestada pelo menos desde o Plano Regional dos Açores do ano de i996, aprovado pela Resolução da Assembleia Legislativa Regional 5/96/A, de 29 de março.
} 
sustentável». Mais: «um conjunto de certificações concedidas a nível internacional demonstra o nível de qualidade que os Açores alcançaram: Rede Natura 2000, Reservas da Biosfera, Rede Europeia de Destinos de Excelência, QualityCost, EcoEscolas e Bandeira Azul, entre muitos outros, reconhecem o bom caminho efetuado, exigindo uma articulação de políticas no sentido da manutenção da imagem de qualidade ambiental que os Açores granjeiam a nível nacional e internacional».

\section{Regime de proteção aplicável}

Em Portugal não existe um diploma legal específico estabelecendo um regime jurídico, de âmbito nacional, para enquadramento das reservas classificadas pela Unesco.

Assim, as regras aplicáveis às reservas, que em Portugal integram a rede mundial da Unesco, decorrem do regime geral da conservação da natureza e biodiversidade, aprovado pelo Decreto-Lei I42/2008, de 24 de julho.

Em função da organização do Estado português - estado unitário e não federal, mas com duas regiões autónomas com competências próprias - o regime geral pode ser adaptado, pelos governos regionais, à realidade insular. Foi o que aconteceu na Região Autónoma dos Açores que, através do Decreto Legislativo Regional I5/20I2/A, de 2 de abril adaptou o regime geral ao território Açoriano. A Região Autónoma da Madeira limitou-se a transpor as diretivas aves e habitats para o território regional ${ }^{6}$, pelo que o regime geral do Decreto-Lei I42/2008, de 24 de julho, vigente para o continente, se aplica naquela região insular sem especificidades.

\section{III.I. Regime geral da conservação da natureza e biodiversidade}

A primeira Lei de conservação da natureza -Lei 9/70, de i9 de junho- remonta ao Estado Novo tendo sido aprovada por Marcelo Caetano em i970. Nela não encontramos quaisquer referências à proteção internacional da natureza, embora as categorias de proteção aí consagradas -de parque nacional e de reserva- resultem dos desenvolvimentos internacionais ${ }^{7}$. Reconhece-se igualmente a importância dos usos turísticos dos espaços naturais, com a criação de reservas turísticas destinadas «a conservação natural e a harmonia das construções» (Base IV 2. d), em conformidade com os objetivos do parque, e subordinadas a um certo ordenamento territorial.

Depois da revolução democrática do 25 de Abril foi aprovado o Decreto-lei 613/76, de 27 de julho, que já reflete alguma preocupação de alinhamento com as correntes europeias: «A introdução neste decreto-lei da concepção europeia de parque natural vem de encontro às realidades geográficas e demográficas do País, cujas paisagens humanizadas

S O artigo 225 da Constituição da República Portuguesa, sobre o regime político-administrativo dos Açores e da Madeira esclarece que este regime se fundamenta «nas suas características geográficas, económicas, sociais e culturais e nas históricas aspirações autonomistas das populações insulares».

${ }^{6}$ Através do Decreto Legislativo Regional 5/2006/M, de 2 de março.

${ }^{7}$ Tal como refere, mais de 20 anos mais tarde o Decreto-lei I9/93, de 23 de janeiro: «Com a Lei n. ${ }^{\circ}$ 9/70, de I9 de junho, que introduziu na nossa ordem jurídica as noções de parque e reserva, teve início o acompanhamento da evolução internacional de protecção da Natureza, através da classificação das áreas mais representativas do património natural» (preâmbulo, 『I). 
resultam de uma intervenção por vezes milenária e praticamente estendida a todo o espaço físico do território», refere o preâmbulo.

Após I7 anos de vigência, o Decreto-lei 19/93, de 23 de janeiro, vem revogar a Lei de I976 e instituir um novo regime legal cujos objetivos são amplamente coincidentes com as finalidades das reservas de biosfera. Além da preservação de espécies, habitats, recursos genéticos, biótopos, sítios, paisagens, formações geológicas e geomorfológicas, são ainda objetivos da classificação «a promoção do desenvolvimento sustentado da região, valorizando a interação entre as componentes naturais e humanas e promovendo a qualidade de vida das populações» (artigo $3^{\circ}$ i) e «a valorização de actividades culturais e económicas tradicionais assente na proteção e gestão racional do património natural» (artigo $3^{\circ}$ j). Inspirada pela primeira e emblemática Lei de Bases do Ambiente (Lei II/97, de 7 de $a b r i 1^{8}$ ) é criada também a Rede Nacional de Áreas Protegidas.

Atualmente é o Decreto-Lei $142 / 2008$, de 24 de julho, que estabelece o regime jurídico da conservação da natureza e da biodiversidade, aplicando-se ao conjunto dos valores e recursos naturais presentes no território nacional e nas águas sob jurisdição nacional.

Segundo este diploma legal, a Rede Fundamental de Conservação da Natureza é composta por dois tipos de áreas: as áreas integradas no sistema nacional de áreas classificadas e algumas áreas de continuidade.

As primeiras incluem as áreas pertencentes à rede nacional de áreas protegidas, os sítios da Rede Natura 2000, as zonas de proteção especial das aves e «as demais áreas classificadas ao abrigo de compromissos internacionais assumidos pelo Estado Português». É aqui que entram os compromissos assumidos perante a Unesco, relativamente às reservas de biosfera.

Trata-se da primeira consagração legal das reservas de biosfera numa Lei geral de conservação da natureza.

A Lei afirma-o claramente: «São consideradas áreas classificadas por instrumentos jurídicos internacionais de conservação da natureza e da biodiversidade, de que Portugal seja parte, todas as áreas que obtenham tal reconhecimento nos termos previstos no instrumento jurídico internacional aplicável em função das suas caraterísticas, designadamente ao abrigo: a) do Programa Man and Biosphere, da Organização das Nações Unidas para a Educação, Ciência e Cultura (UNESCO), lançado em I970»” (artigo 27 n. ${ }^{\circ}$ 2).

Porém, se em relação às zonas integradas na rede nacional de áreas protegidas, a Lei estabelece os objetivos da classificação, já não é assim nem em relação aos sítios da Rede Natura 2000 ou Zonas de Proteção Especial das Aves, nem em relação às áreas classificadas ao abrigo de compromissos internacionais -como é o caso do Programa Homem e Biosfera, da Unesco.

Com efeito, para os parques nacionais, parques naturais, reservas naturais, paisagens protegidas e monumentos naturais, determina a Lei que «a classificação de uma

\footnotetext{
${ }^{8}$ Posteriormente substituída pela Lei i9/20I4, de I4 de abril.

9 No elenco do artigo 27 seguem-se a Convenção de Ramsar sobre Zonas Húmidas de Importância Internacional Especialmente como «Habitat» de Aves Aquáticas (de I97I), a Convenção Ospar para a Protecção do Meio Marinho do Atlântico Nordeste (de I992), etc.
} 
área protegida visa conceder-lhe um estatuto legal de proteção adequado à manutenção da biodiversidade e dos serviços dos ecossistemas e do património geológico, bem como à valorização da paisagem» (artigo I $2^{\circ}$ ).

Em relação aos sítios da Rede Natura 2000 e Zonas de Proteção Especial das Aves, a Lei limita-se a fazer o que designa por «uma remissão enquadradora», reenviando para outra Lei ${ }^{\text {io }}$ que estabelece um regime legal específico (artigo 25).

Já em relação às áreas protegidas transfronteiriças e às áreas abrangidas por designações de conservação de caráter supranacional, a estratégia do legislador consistiu em prever:

— primeiro, a sobreposição de classificações;

- depois, a redução da proteção supranacional ao regime legal nacional ou europeu- aplicável.

Vejamos como se processa especificamente a proteção das zonas que beneficiam de designações internacionais, nas quais se enquadram as reservas de biosfera integrantes da rede mundial da Unesco.

Nas palavras da Lei, «tendo por objectivo o reforço da protecção e a manutenção da biodiversidade e dos recursos naturais e culturais associados, podem ficar abrangidas por designações de conservação de carácter supranacional, em particular as estabelecidas por convenções ou acordos internacionais de que Portugal seja parte, áreas delimitadas no território nacional ou nas águas marítimas sujeitas a jurisdição nacional, coincidentes com áreas protegidas integradas na RNAP ou com áreas que integrem a Rede Natura 2000, cujos valores naturais sejam reconhecidos como de relevância supranacional» (artigo 27 n. $\left.{ }^{\circ} \mathrm{I}\right)$.

Em termos mais simples, e interpretando a Lei para aplicar ao caso concreto das reservas de biosfera, o que a Lei diz é que, quando os valores presentes num parque nacional, num parque natural, numa reserva natural, numa paisagem protegida ou num monumento natural tiverem relevância internacional, poderão (é de notar o caráter não imperativo da estatuição) ser candidatados ao reconhecimento internacional como reservas de biosfera, sem que isso implique alteração necessária no regime de proteção aplicável.

Efetivamente, a Lei determina que «quando as áreas previstas no presente artigo coincidam com áreas protegidas de âmbito nacional, regional ou local, é-lhes aplicável o regime constante dos respectivos actos de classificação ou planos de ordenamento, quando existentes» (artigo $27 \mathrm{n}^{\circ}$ 3). Daqui resultam várias consequências:

I. O regime de proteção aplicável às novas reservas de biosfera é apenas o regime geral existente.

2. Se o ato de classificação não definir os princípios de gestão e não previr um regime de interdições e condicionamentos, o regime existente é francamente insuficiente.

3. Se as reservas de biosfera não coincidirem com áreas da rede nacional estamos perante uma lacuna real, por ausência de regime legal de proteção aplicável ${ }^{\mathrm{II}}$.

${ }^{\text {ro }}$ Atualmente é o Decreto-Lei ${ }^{\circ}$ 49/2005, de 24 de fevereiro, que altera e republica o Decreto-Lei I40/99, de 24 de abril. 
4. Mesmo que não existam planos de ordenamento da área protegida - que é também uma reserva de biosfera - a Lei não obriga à sua elaboração.

A explicação da razão de ser da sobreposição de designações, mantendo o mesmo regime jurídico, encontramo-la na Estratégia Nacional de Conservação da Natureza e da Biodiversidade de 200I. Vale a pena acompanhar de perto o raciocínio do legislador: «a Rede Fundamental de Conservação da Natureza é, assim, um conceito abrangente que promove a visão integrada do património e dos recursos naturais sujeitos por lei ou compromisso internacional a um especial estatuto jurídico de proteção e gestão, sem implicar, portanto, a atribuição de um regime complementar ao já existente. (...) O objectivo da introdução de um conceito como o de Sistema Nacional de Áreas Classificadas é o de assegurar, por via de uma Lei-quadro da conservação da Natureza, a integração e a regulamentação harmoniosa das diferentes áreas já sujeitas a um estatuto ambiental de protecção, clarificando o regime jurídico aplicável nas situações de sobreposição e o alcance no ordenamento jurídico de algumas das figuras existentes, como as zonas húmidas classificadas no âmbito da Convenção de Ramsar, as reservas da biosfera, as reservas biogenéticas, as áreas com o diploma europeu do Conselho da Europa e as áreas classificadas como património mundial também em razão do seu património natural ou paisagístico» ${ }^{12}$.

Numa interpretação pessoal parece-nos que, mais do que a «integração e regulamentação harmoniosa», no fundo, o que se espera é que ao agraciar áreas naturais nacionais dedicadas à conservação com o rótulo reserva de biosfera - Unesco, venham implicitamente associadas ao rótulo uma série de vantagens: o reforço inerente da proteção dos valores naturais, chances de desenvolvimento turístico, oportunidades de reforço da identidade local, condições de preservação de tradições culturais sustentáveis, etc.. O raciocínio é este: se um determinado parque natural, além de ser uma zona de conservação da rede nacional de áreas protegidas, ainda for uma reserva de biosfera integrada numa rede mundial, é expectável que a sua importância seja levada mais «a sério» tanto pelos atores sociais e institucionais envolvidos como pelos próprios cidadãos.

Uma prova das dimensões de promoção turística associadas à atribuição do «rótulo Unesco» é, por exemplo, o Plano Regional de Ordenamento do Território dos Açores (PROTA) que, entre as normas gerais, inclui a necessidade de «adoptar medidas de valorização da classificação como Reserva da Biosfera $»^{13}$ da ilha do Corvo.

Mais recentemente, as declarações da Assembleia Legislativa da Região Autónoma dos Açores, proferidas em abril de 20I3, em relação à reserva natural do Corvo, a propósito das obras de ampliação e modernização do Porto da Casa, são ainda mais claras. Aquela Assembleia Legislativa destaca que «este [turismo náutico] deve ser, como é evidente, contextualizado e integrado no âmbito do turismo de natureza ${ }^{\mathrm{T} 4}$, vertente turística para a

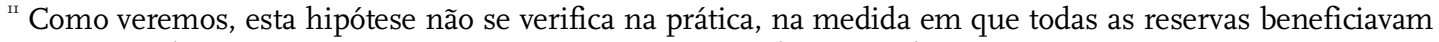
de um estatuto de protecção anterior. Em teoria, no entanto, a lacuna poderia ocorrer.

${ }^{12}$ Resolução do Conselho de Ministros I52/200I, de II de outubro de 200I, que aprova a Estratégia Nacional de Conservação da Natureza e da Biodiversidade.

${ }^{13}$ Decreto Legislativo Regional 26/20Io/A que aprova o Plano Regional de Ordenamento do Território dos Açores (PROTA).

${ }^{14}$ O Programa Nacional de Turismo de Natureza foi criado pela Resolução do Conselho de Ministros n. ${ }^{\circ}$ II2/98, de 25 de agosto.
} 
qual a ilha do Corvo, dada a sua condição de Reserva da Biosfera da UNESCO, possui um grande potencial» ${ }^{\mathrm{IS}}$.

De forma ainda mais clara, o Plano Estratégico Nacional do Turismo ${ }^{\mathrm{r} 6}$ realça, relativamente ao turismo de natureza, como «elementos qualificadores do destino», a existência de reservas da Biosfera, designadamente nos Açores e na Madeira.

Já em 20I5, o Despacho sobre a Comissão nacional MaB afirma que «a existência de reservas da biosfera nacionais, áreas reconhecidas pela UNESCO e com importante divulgação mundial, capacita -as como modelo de sustentabilidade, particularmente privilegiados para o turismo e visitação» ${ }^{17}$. Neste contexto é importante referir a publicação, em 3 de Setembro de 20I5, de importantes alterações ao regime jurídico do turismo de natureza em áreas do Sistema Nacional de Áreas Classificadas, que reforça a importância deste segmento do mercado turístico ${ }^{\mathrm{I}}$.

Em suma, o estatuto Unesco é visto como um plus, como uma «cereja em cima do bolo» que vem reforçar a esperança de desenvolvimento sustentável em zonas sem grandes recursos económicos, mas com elevado potencial natural.

As conclusões do estudo levado a cabo pela Universidade de Trás os Montes e Alto Douro e publicado pela Comissão Macional da Unesco em dezembro de 20I4, sobre o «Valor económico da ligação às redes Unesco em Portugal», confirmam esta ideia: «o impacto na actividade económica decorrente da chancela Unesco é positivo na generalidade dos indicadores, nos grupos de bens em consideração, sendo plausível concluir que as classificações Unesco propulsionam benefícios para a região envolvente» ${ }^{\text {19}}$. Em relação às reservas de biosfera, esses custos de preparação da candidatura são estimados, em média, em I4250€, sendo o tempo de preparação médio de 5 meses e 3 semanas. Por ano, os custos de preparação da candidatura são, na média de todas as reservas, de 2760€; 5,7 dias de dedicação e 4 pessoas afetadas (recursos humanos). Quanto aos benefícios, 29\% são para o Governo (274703€), I9\% são benefícios privados (274628€), e 52\% são benefícios externos $(500000 €)$. Os benefícios externos têm a ver com a melhoria da imagem da região e a sua atratividade, bem como vantagens para a componente urbana envolvente, e são a componente mais importante do retorno da chancela Unesco.

III.2. Regime de conservação da natureza e biodiversidade nos Açores

O Decreto Legislativo Regional I5/2012/A, de 2 de abril, cumpre duas missões: primeiro, adaptar o regime geral ao arquipélago, e segundo, transpor as diretivas aves e habitats para o território açoriano.

\footnotetext{
${ }^{15}$ Resolução da Assembleia Legislativa da Região Autónoma dos Açores 6/20I3/A, de I6 de abril.

${ }^{16}$ Aprovado pela Resolução do Conselho de Ministros 24/20I3, de I6 de abril.

${ }^{17}$ Preâmbulo do Despacho 9051/2015, de I3 de agosto.

${ }^{\mathrm{r} 8}$ Decreto-lei n. ${ }^{\circ} \mathrm{I} 86 / 2015$, de 3 de setembro.

${ }^{19}$ Página 62 do estudo, disponível em

https://www.unescoportugal.mne.pt/images/Comunica\%C3\%A7\%C3\%A30/relatorio_cnu_final_04.pdf.

O estudo, que não analisa apenas as reservas de biosfera, mas também sobre sítios do património mundial, geoparques e cátedras Unesco, analisa o custo anual da afiliação, os benefícios diretos e indiretos e as fontes de receita.
} 
Sabendo que, das oito reservas portuguesas, três se situam em território dos Açores $^{20}$, não é de admirar que o diploma legal comece com a afirmação da «relevância a nível planetário» do arquipélago dos Açores e da região oceânica que o rodeia. Primeiro, por ser «um importante repositório de biodiversidade». Depois, pela exuberância, exotismo e endemismo caraterísticos da região da macaronésia. Por fim, pelas «naturais vulnerabilidades resultantes da pequena extensão dos ecossistemas insulares, do isolamento entre ilhas e em relação às regiões continentais, da fragmentação e perda de habitats e da fragilidade das espécies autóctones face a organismos invasores». Estas são as especificidades que justificam a necessidade de um regime legal próprio.

E é nesse mesmo regime legal que encontramos toda uma secção da Lei -a secção $\mathrm{V}-$ toda ela dedicada às reservas de biosfera. Objetivos, plano de ação, gestão das reservas de biosfera e Conselho de Gestão das reservas de biosfera são os tópicos autonomamente regulados.

Aqui, são dignas de nota três opções legislativas:

Explicitação dos objetivos da instituição das reservas de biosfera, a saber, a promoção de «abordagens socioeconómicas que, aliando conhecimentos científicos e estratégias de governança, visem reduzir a perda de biodiversidade e melhorar os meios de subsistência das populações» (artigo 5I n. ${ }^{\circ} \mathrm{I}$ ). De forma ainda mais concreta, «as reservas de biosfera visam favorecer as condições sociais, económicas e culturais essenciais à viabilidade do desenvolvimento sustentável, podendo servir também como locais pedagógicos e de experimentação» (artigo $5 \mathrm{I} \mathrm{n}^{\circ}{ }^{\circ}$ 2).

— Exigência de um plano de ação para cada reserva. O plano de ação será trienal e dele devem constar as ações a desenvolver no período em causa, um programa de educação ambiental para os residentes e ações de promoção interna e externa (artigo 52).

- Em termos de organização, sempre que a reserva de biosfera coincida territorialmente com um parque, o funcionamento da reserva e o cumprimento dos objetivos definidos são competências do Conselho de Gestão da reserva que assume as competências e substitui o Conselho Consultivo do parque natural, o que revela bem a importância atribuída às reservas (artigo 53 e 54).

III.3. Relação entre as reservas de biosfera e a rede nacional de áreas protegidas

Olhando em concreto para cada uma das reservas Unesco, verificamos que todas elas já beneficiavam de um estatuto de proteção nacional -reserva natural, parque natural, parque nacional, ou reserva florestal natural-, anteriormente à sua classificação internacional como reservas de biosfera.

No entanto, aquando da atualização deste estatuto, nem todas passaram a incluir referências ao estatuto Unesco, ou sequer a adequar o regime aplicável às exigências desta classificação internacional.

${ }^{20}$ Futuramente, se a candidatura de São Jorge a reserva de biosfera for concluída, entregue e aprovada, haverá, nos Açores quatro das oito reservas portuguesas. 


\begin{tabular}{|c|c|c|c|c|}
\hline & 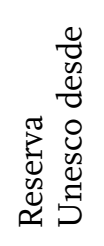 & 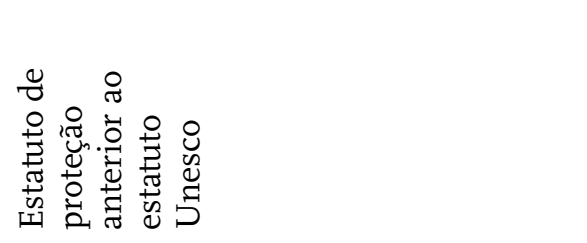 & 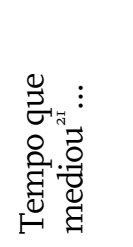 & 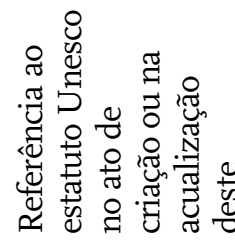 \\
\hline Boquilobo & I98I & $\begin{array}{l}\text { Reserva natural }{ }^{22} \text { desde } 1980 \\
\text { Decreto-lei I98/80 }\end{array}$ & I ano & Sim, em I997 \\
\hline Graciosa & 2007 & $\begin{array}{l}\text { Reserva florestal natural }{ }^{23} \text { desde I9 } 88 \\
\text { Decreto Legislativo Regional 27/88/A }\end{array}$ & I9 anos & Sim, em 2008 \\
\hline Corvo & 2007 & $\begin{array}{l}\text { Parque natural }{ }^{24} \text { desde } 2006 \\
\text { Decreto Legislativo Regional 56/2006/A }\end{array}$ & I ano & Não \\
\hline Flores & 2009 & $\begin{array}{l}\text { Reserva florestal natural }{ }^{25} \text { desde I9 } 88 \\
\text { Decreto Legislativo Regional 27/88/A } \\
\text { Parque natural }{ }^{26} \text { desde } 201 \mathrm{I} \\
\text { Decreto Legislativo Regional 8/20II/A }\end{array}$ & 2I anos & Sim, em $201 \mathrm{I}$ \\
\hline Gerês & 2009 & Parque nacional $^{27}$ desde I97I & 38 anos & Não \\
\hline
\end{tabular}

\footnotetext{
${ }^{21}$ Tempo decorrido entre a primeira classificação nacional e a atribuição do estatuto Unesco.

${ }^{22}$ Segundo a primeira lei de conservação da natureza após a revolução de 25 de Abril de I974 (Decreto-Lei 613/76 de 27 de julho), nas reservas naturais a protecção dizia «respeito a todos os aspectos da Natureza, impedindo-se qualquer ação que altere a dinâmica dos respectivos eco-sistemas e onde a presença humana só seja admitida por razões administrativas ou científicas».
}

${ }^{23}$ Reservas florestais eram «áreas situadas dentro dos perímetros florestais, núcleos florestais e em outras zonas sob a administração da Secretaria Regional da Agricultura e Pescas (SRAP) que, numa ótica de uso múltiplo, se revestem de interesse científico nos aspetos botânico, geológico ou hidrológico e de valor para a protecção da natureza e de ecossistemas florestais, para a cultura e ensino ou para a prática de recreio, turismo e defesa paisagística» (artigo $2^{\circ}$ do Decreto Legislativo Regional I5/87/A de 24 de julho). As reservas florestais naturais contrapõem-se às reservas florestais de recreio e são« áreas de maior interesse ecológico e importância científica para a protecção de ecossistemas, da flora, da fauna, da paisagem e de outros aspectos físicos» (artigo $5^{\circ}$ n. ${ }^{\circ}$ I do mesmo Decreto Legislativo Regional).

${ }^{24} \mathrm{O}$ enquadramento jurídico do parque natural é ainda o Decreto Legislativo Regional 2I/93/A, de 23 de dezembro, que adapta o regime geral de conservação da natureza (Decreto-lei I $9 / 93$ de 23 de janeiro) à região dos Açores. Nos termos deste diploma, os parques naturais regionais são «áreas que se caracterizam por conter paisagens naturais, seminaturais e humanizadas, de interesse nacional, sendo exemplo de integração harmoniosa da actividade humana e da natureza e que apresenta amostras de um bioma ou região natural» (artigo $7^{\circ}$, n. ${ }^{\circ}$ I do Decreto-lei I9/93, aplicável por força do artigo $5^{\circ}$, n. ${ }^{\circ}$ I c) do Decreto Legislativo Regional).

${ }^{25}$ É aplicável o mesmo regime da ilha Graciosa. Vide nota n. ${ }^{\circ} 2 \mathrm{I}$.

${ }^{26}$ Aplica-se o mesmo regime descrito para a ilha do Corvo. Vide nota n. ${ }^{\circ} 22$.

${ }^{27}$ Nos termos da Lei 9/70, de I9 de junho, que atribuía ao Governo a incumbência de promover a proteção da Natureza e dos seus recursos em todo o território, os parques nacionais podiam abranger as seguintes zonas de reserva:

«a) Reservas integrais-áreas protegidas, onde se desenvolve o livre jogo dos factores ecológicos naturais sem qualquer intervenção exterior;

b) Reservas naturais-território destinado, mediante adequadas providências, à proteção e conservação da flora e da fauna naturais, bem como da paisagem;

c) Reservas de paisagem-espaços destinados à proteção e conservação dos locais e paisagens, assim como à protecção, consolidação, conservação e restauro de construções de interesse etnográfico ou técnico;

d) Reservas turísticas-zonas a desenvolver segundo as necessidades das populações e do turismo, em conformidade com os objectivos do parque, e subordinadas a um ordenamento destinado a favorecer a sua unidade e conservação natural e a harmonia das construções». 
Decreto $187 / 7 \mathrm{I}$

\begin{tabular}{|c|c|c|c|c|}
\hline & & Decreto $187 / 7 \mathrm{I}$ & & \\
\hline Berlengas & $20 I I$ & $\begin{array}{l}\text { Reserva natural }{ }^{28} \text { desde I98I } \\
\text { Decreto-lei } 264 / 8 \mathrm{I}\end{array}$ & 30 anos & Não \\
\hline Santana & $20 I I$ & $\begin{array}{l}\text { Parque natural }{ }^{29} \text { desde I9 } 82 \\
\text { Decreto regional I4/82/M }\end{array}$ & 29 anos & Não \\
\hline Meseta Ibérica & 2015 & $\begin{array}{l}\text { Parque natura }{ }^{30} \text { desde } 1979 \\
\text { Decreto-lei 355/79 (Montesinho) } \\
\text { Parque natural }{ }^{31} \text { desde I99 } 8 \text { - Decreto } \\
\text { Regulamentar 8/98 (Douro) }\end{array}$ & $\begin{array}{l}36 \text { anos } \\
\text { I7 anos }\end{array}$ & Não \\
\hline São Jorge & --- & $\begin{array}{l}\text { Reserva florestal natural }{ }^{32} \text { desde I988 } \\
\text { Decreto Legislativo Regional 27/88/A } \\
\text { Parque natural33 desde 20II } \\
\text { Decreto Legislativo Regional Io/20II/A }\end{array}$ & $>27$ anos & Não \\
\hline
\end{tabular}

Por isso, podemos concluir preliminarmente que o «rótulo Unesco» se traduziu apenas num reforço da visibilidade, da importância e da legitimidade da proteção, mas, na generalidade dos casos, não se traduziu em proteção legal acrescida. Na realidade, em Portugal, raramente a classificação Unesco desencadeou alterações normativas. De facto, quando existem instrumentos normativos mais recentes, que atualizam o diploma inicial de criação da zona da rede nacional de proteção, modernizando o regime jurídico aplicável ao sítio, o estatuto de reserva de biosfera nem sequer é referido ou, quando muito, é apenas referido superficialmente, não se aproveitando o ensejo para criar um regime diferente e

${ }^{28}$ Ainda na vigência do Decreto-Lei 613/76, de 27 de julho, aplica-se o mesmo regime descrito para o Paul de Boquilobo. Vide nota n. ${ }^{\circ} 20$.

${ }^{29} \mathrm{O}$ Parque visa o «ordenamento biofísico das serras da Madeira com vista ao recreio de ar livre e à protecção da natureza» (artigo $2^{\circ}$ a) do Decreto regional I4/82/M) e «a promoção económica, social e cultural das populações, abrangidas na sua área, com participação activa das mesmas» (artigo $2^{\circ}$ b) do mesmo diploma regional). Pretende-se que o parque seja «uma forma orgânica de desenvolvimento, com respeito pelas bases biofísicas e ecológicas do ambiente e pelas tradições culturais das populações« (preâmbulo).

${ }^{30}$ Nos termos do Decreto-Lei 613/76, de 27 de julho, parques naturais eram «áreas de território, devidamente ordenadas, tendo em vista o recreio, a conservação da Natureza, a protecção da paisagem e a promoção das populações rurais, podendo incidir sobre propriedade pública ou privada e onde o zonamento estabelece as aptidões e usos das diferentes parcelas de terreno» (artigo 2 n. ${ }^{\circ}$ ).

3I A lei de conservação da natureza em vigor ao tempo era o Decreto-lei iو/93, de 23 de janeiro, que definia um parque natural como «uma área que se caracteriza por conter paisagens naturais, seminaturais e humanizadas, de interesse nacional, sendo exemplo de integração harmoniosa da actividade humana e da natureza e que apresenta amostras de um bioma ou de uma região natural» (artigo 7).

${ }^{32}$ Vale aqui o que foi dito para as ilhas Graciosa e Flores. Vide nota n. ${ }^{\circ} 2 \mathrm{I}$.

${ }^{33}$ O Parque Natural de São Jorge constitui uma «unidade coerente e integrada, pautada por objectivos de gestão e conservação que contempla espaços com particulares aptidões para a conservação da natureza, da paisagem e dos recursos naturais, assente em critérios científicos de classificação, balizados por orientações internacionais, nacionais, regionais e locais» (Decreto Legislativo Regional Io/20II/A) com enquadramento no Decreto Legislativo Regional I5/2007/A, de 25 de junho, que estabelece a Rede Regional de Âreas Protegidas dos Açores. Os parques naturais incluem áreas de protecção integral, parcial e complementar; áreas prioritárias para a conservação, áreas de uso sustentável de recursos e áreas de intervenção específica (artigos I9 a 25 do Decreto Legislativo Regional I5/2007/A). 
autónomo de proteção e gestão adequado aos objetivos Unesco, nomeadamente no que respeita às questões de sustentabilidade e participação.

A principal exceção é a reserva natural da Graciosa. Em Novembro de 2008, foi criado o Parque Natural da Ilha Graciosa, que passou a integrar todas as categorias de áreas protegidas da Ilha Graciosa. Razão determinante para a adoção do novo regime legal foi o «facto da Ilha Graciosa ter sido classificada em Setembro de 2007, no âmbito do Programa 'O Homem e a Biosfera' da United Nations, Educational, Scientific and Cultural Organization - UNESCO, como Reserva da Biosfera. Os objetivos que decorrem desta classificação são a preservação da riqueza e diversidade geológica, das espécies e habitats importantes, das tradições e do património cultural local e da melhoria das condições de vida da população, de forma ambiental e culturalmente sustentada, valores que em tudo se harmonizam e integram com os objectivos, critérios de gestão e sistema de classificação da IUCN. A Reserva da Biosfera da Ilha Graciosa integra áreas classificadas sob diferentes denominações e uma área proposta como IBA que não se deixou de ter em atenção» ${ }^{34}$.

Em termos de objetivos, os do Parque Natural são tripartidos: «os objectivos gerais e de gestão próprios da Rede Regional de Áreas Protegidas e os objectivos específicos inerentes às categorias de áreas protegidas nele existentes e os decorrentes da classificação da Ilha Graciosa como Reserva da Biosfera» ${ }^{35}$.

Quanto à categorização de espaços, o Parque Natural de Ilha Graciosa optou por adotar a nomenclatura da União Internacional para a Conservação da Natureza ${ }^{36}:$ a) reserva natural (IUCN I); b) monumento natural (IUCN III); c) área protegida para a gestão de habitats ou espécies (IUCN IV); $d$ ) área de paisagem protegida (IUCN V) e $e$ ) área protegida de gestão de recursos (IUCN VI). Cada categoria integrada do parque natural goza de um regime próprio, consistindo na listagem de atividades interditas, na listagem de atividades dependentes de parecer prévio vinculativo da administração, e ainda atividades que podem ser condicionadas em termos de áreas e períodos.

Também a reserva natural das Flores, é, em certa medida, uma exceção já que a fundamentação legal para a criação do parque natural das Flores, em 20II assentou, em grande medida, na inclusão de grande parte da ilha na rede mundial de reservas da biosfera, dois anos antes. Nos termos da Lei «a inclusão da ilha das Flores na rede mundial de reservas da biosfera, bem como a aplicação do Decreto Legislativo Regional 15/2007/A, de 25 de junho, que consagrou o regime jurídico de classificação, gestão e administração da Rede Regional de Áreas Protegidas dos Açores, justificam a criação do Parque Natural das Flores, incluindo todas as suas áreas naturais num contexto de contínuo ecológico, enquanto princípio subjacente à criação de redes integradas de conservação da natureza» ${ }^{37}$.

\footnotetext{
${ }^{34}$ Preâmbulo do Decreto Legislativo Regional n. ${ }^{\circ}$ 45/2008/A, de 5 de novembro de 2008.

${ }^{35}$ Artigo 2 do Decreto Legislativo Regional n. ${ }^{\circ}$ 45/2008/A, de 5 de novembro de 2008.

${ }^{36}$ Definida nas Guidelines for protected area management categories IUCN de I994, do World Conservation Union (disponíveis em

http://www.iucn.org/about/work/programmes/gpap_home/gpap_quality/gpap_pacategories/)

e com o propósito expresso de contribuir para o «reconhecimento internacional dos valores conservacionistas, paisagísticos e científicos dos Açores» face à «proliferação de figuras legais de áreas com interesse para a conservação da natureza», tal como declarado no Decreto Legislativo Regional I5/2007/A que reclassifica a Rede Regional de Áreas Protegidas dos Açores.
}

${ }^{37}$ Decreto Legislativo Regional 8/20II/A, de 23 de março. 
Além disso, o parque integra ainda as designações de zona de proteção especial das aves, zona especial de conservação, e «Important bird areas».

Quanto aos objetivos de gestão do Parque Natural da Ilha das Flores são compatíveis com os fins das reservas de biosfera, a saber:

a) Preservação de habitats, ecossistemas e espécies num estado favorável;

b) Manutenção de processos ecológicos;

c) Proteção das características estruturais da paisagem e dos seus elementos geológicos;

d) Preservação de exemplos do ambiente natural para estudos científicos, monitorização e educação ambiental;

e) Conservação das condições naturais de referência aos trabalhos científicos e projetos em curso;

f) Definição de limites e condicionamentos ao acesso público.

Relativamente a planos de ação para as reservas de biosfera, nos Açores, o Plano Regional Anual para 2010 (aprovado pelo Decreto Legislativo Regional 2/2010/A) apontava como prioridade, quanto ao ambiente e ordenamento do território «gerir com eficiência o território promovendo a qualidade ambiental». Para o efeito, determinava a elaboração e implementação de «planos de acção das reservas da biosfera a integrar nos planos de ordenamento dos parques naturais de ilha». Porém, até hoje, esta intenção não saiu do papel, sendo a reserva Gerês-Xurês a única com plano de ação (em consulta pública durante o mês de abril de $2015^{38}$ ).

Relativamente à reserva do Paul de Boquilobo, os objetivos das reservas de biosfera da Unesco são referidos no diploma que reclassifica a reserva natural em i997. No artigo $3^{\circ}$, identifica-se como objetivo específico da Reserva Natural a «elaboração de estudos científicos que fundamentem as acções de conservação e permitam uma cooperação de âmbito internacional no quadro da rede de reservas da biosfera» (alínea d)). Outros objetivos são «preservar e melhorar as condições de habitat para as espécies dependentes do paul, especialmente avifauna aquática, com particular incidência no núcleo central da Reserva», «favorecer a diversidade de biótopos nas zonas envolventes do núcleo central, tendo por objetivo a criação de uma zona tampão, nomeadamente pela progressiva renaturalização de algumas parcelas» e «compatibilizar os objetivos de conservação com as actividades agrícolas, silvícolas e pastoris da periferia da reserva, tendo como objectivo a criação de uma zona de transição, na qual se possam levar a cabo acções demonstrativas da integração entre conservação da natureza e exploração dos recursos».

Em 2005, o Decreto Regulamentar 2/2005, de 23 de março, amplia os limites geográficos da reserva natural e acrescenta os objetivos de «ordenamento das utilizações recreativas e da acessibilidade pública» e de «monitorização de espécies e habitats» não só

\footnotetext{
${ }^{38}$ Disponível em http://www.turismoruraleparquesdecampismogeres.com/noticias_bi.php?id_noticia=203
} 
nas reservas da biosfera, como noutras áreas de proteção internacional: as zonas de proteção especial para as aves, e as zonas húmidas de importância internacional (sítios Ramsar) ${ }^{39}$.

Por outro lado, no Plano Diretor Municipal da Golegã ${ }^{40}$, o Paul de Boquilobo é identificado como uma «zona húmida de grande valor ecológico e ornitológico, integrada na Rede Internacional de Reservas da Biosfera» sendo a sua proteção «regulamentada pela legislação de conservação da natureza em vigor $»^{41}$... a qual é francamente insuficiente, como já tivemos oportunidade de verificar.

E estas são as únicas referências que encontramos nos diplomas de classificação ou nas atualizações destes.

Face ao panorama descrito, o parecer desfavorável da Unesco relativamente ao primeiro relatório de revisão periódica para o Paul de Boquilobo, apresentado por Portugal em 20I4, já não é tão surpreendente. No seu parecer, o Comité Consultivo da Unesco considerou que a reserva não cumpria os requisitos estatutários da rede mundial das reservas de biosfera e recomendou ${ }^{42}$ que fosse fornecido um mapa com o zonamento corrigido $^{43}$, que fosse fornecida informação sobre a governação da reserva e sobre o envolvimento das pessoas nos processos de decisão e gestão.

Tudo o que foi dito não significa que, na prática, as reservas de biosfera (todas, ou pelo menos algumas delas) não sejam geridas ativamente e em sintonia com os objetivos da Unesco, em função dos conhecimentos e competência profissional dos responsáveis ${ }^{44}$ pela gestão da zona da protecção nacional territorialmente coincidente. Significa é que, na generalidade dos casos (com excepção dos Açores), não existe uma obrigação legal de o fazer, nem diretrizes legais orientadoras, nem plano de acção enquadrador, nem participação e envolvimento sistemático da população.

O conjunto das atividades de conservação, protecção, investigação, dinamização, divulgação, educação, etc. desenvolvidas em cada reserva pode ser visto nos relatórios de atividades apresentado à Unesco no âmbito do Programa o Homem e a Biosfera, preparados pela Comissão $\mathrm{MaB}^{45}$.

\footnotetext{
${ }^{39}$ Artigo $3^{\circ}$ e) do Decreto Regulamentar: «Elaborar estudos científicos, bem como proceder à monitorização de espécies e habitats, que fundamentem as acções de conservação no quadro da rede de zonas de protecção especial para as aves, e de zonas húmidas de importância internacional e de reservas da biosfera».

${ }^{40}$ Resolução do Conselho de Ministros $n^{\circ}$ 106/2000, de 18 de agosto.

${ }^{41}$ Artigo 32 do Regulamento do Plano Diretor Municipal: «Reserva Natural do Paul do Boquilobo I-.A área da Reserva Natural do Paul do Boquilobo é uma zona húmida de grande valor ecológico e ornitológico, integrada na Rede Internacional de Reservas da Biosfera. 2-.A sua protecção encontra-se regulamentada pela legislação em vigor».

${ }^{42} \mathrm{Na}$ vigésima reunião do International Co-ordinating Council of the Man and the Biosphere Programme, em Paris, de I7 a 20 de março de 2014 (disponível em

http://www.unesco.org/new/fileadmin/MULTIMEDIA/HQ/SC/pdf/SC-I4-CONF-226-

IO_periodic_review_eng2.pdf).

${ }^{43}$ Em 2005 a reserva foi alargada para incluir uma zona de transição mas essa zona não constava na planta de zonamento anexa ao relatório.

${ }^{44}$ De acordo com a informação disponível no portal da Unesco, as autoridades administrativas indicadas como responsáveis, variam de reserva para reserva, a saber: o Instituto da Conservação da Natureza e da Biodiversidade (Berlengas, Boquilobo), a Direcção Regional do Ambiente (Corvo, Flores, Graciosa), a Comissão de Acompanhamento do Parque (Gerês-Xurés), um Agrupamento Europeu de Cooperação Territorial (Zasnet, Meseta Ibérica) e a autarquia local (Santana).

${ }^{45}$ O Relatório para o período 20I4-20I5 está disponível em
} 


\section{Descrição da organização institucional}

O facto de haver, desde I985, um despacho do Secretário de Estado do Ambiente ${ }^{46}$ que constituiu a Comissão Nacional $\mathrm{MaB}^{47}$, que vigorou ininterruptamente até 2015 não significa que, desde então, a Comissão tenha estado em funções. Na realidade, esta estrutura de organização esteve inativa durante $\operatorname{anos}^{4^{8}}$, como confirmam as referências expressas a este facto que encontramos na Estratégia Nacional da Conservação da Natureza e da Biodiversidade de 2009: «a Comissão Nacional MaB reiniciou as suas funções em 2007, após ter estado desactivada durante vários anos». $\mathrm{Na}$ opção estratégica n. ${ }^{\circ}$ IO «Intensificar a cooperação internacional», é referida a importância de «intensificar o acompanhamento por Portugal dos processos de cooperação internacional relevantes para a conservação da Natureza e da Biodiversidade e promover a aplicação das decisões, recomendações e resoluções adoptadas pelos órgãos instituídos no âmbito das convenções internacionais».

Desde 2006, em Portugal, a motivação para o programa o Homem e a Biosfera parece ter ganho um novo fôlego. Através de um Despacho do Ministério do Ambiente ${ }^{49}$ é reativada a Comissão Nacional do Programa Man and the Biosphere com uma nova composição, que integra representantes de diferentes organismos do Estado e da Universidade (áreas das ciências naturais e sociais) ${ }^{50}$. As funções da Comissão são funções genéricas: consultivas, de divulgação, de coordenação e de interface com a Unesco ${ }^{5 \mathrm{I}}$.

http://www.unesco.org/new/fileadmin/MULTIMEDIA/HQ/SC/pdf/MAB_national_report_Portugal_MABI

CC27_en.pdf. O relatório anterior, cobrindo o período 2013-20I4,

está também disponível em

http://www.unesco.org/new/fileadmin/MULTIMEDIA/HQ/SC/pdf/MAB_national_report_Portugal_MABI

CC26_en.pdf

e o relatório de 20I2-20I3 está disponível em

http://www.icnf.pt/portal/naturaclas/ei/resource/doc/mab/rel-mab-I2-I3-en.

${ }^{46}$ Ao tempo o titular da Secretaria de Estado era o Eng ${ }^{\circ}$ Carlos Pimenta, sendo Ministro do Plano e da Administração do Território Luis Valente de Oliveira.

${ }^{47}$ Despacho 43/85, de 7 de outubro.

${ }^{48}$ Mesmo no plano internacional foi só em 2008 que Portugal participou, pela primeira vez, no Congresso Mundial de Reservas da Biosfera e na reunião anual do Comité Íbero-americano (MaB - Rede de Reserva Mundial da Biosfera, UNESCO).

${ }^{49}$ Despacho 2365/2006, de 30 de janeiro, do Secretário de Estado do Ambiente, Humberto Delgado Ubach Chaves Rosa, sendo Ministro Francisco Nunes Correia.

${ }^{50}$ Os elementos da Comissão eram:

a) Pedro António de Castro Henriques, em representação do Instituto da Conservação da Natureza (ICN), que coordena;

b) Gonçalo Jorge Pestana Calado, professor universitário da área das ciências naturais;

c) João Howell Pato, investigador da área das ciências sociais;

d) Luís Filipe da Silva Morbey, na qualidade de representante do Ministério do Ambiente, do Ordenamento do Território e do Desenvolvimento Regional (MAOTDR) na Comissão Nacional da UNESCO; e) Luís Carlos Romana Chaínho, em representação do Gabinete de Relações Internacionais (GRI) do MAOTDR.

${ }^{5 \mathrm{I}}$ Mais concretamente, tem as seguintes funções:

a) Divulgar as bolsas MAB Young Scientists e o prémio Sultão Qaboos, receber as candidaturas nacionais e remetê-las à UNESCO;

b) Coordenar o envio de candidaturas nacionais para a classificação de novas reservas da biosfera;

c) Representar Portugal nas reuniões do Comité Científico do MAB e nas reuniões do Bureau do MAB;

d) Organizar sessões públicas relacionadas com o Programa MaB que considere pertinentes;

e) Pronunciar-se, quando solicitado, nos processos de participação de Portugal noutros programas 
A submissão e aprovação de sete novas reservas entre a reativação da Comissão, em 2006, e o momento presente é a prova da vitalidade renovada do tema das reservas de biosfera em Portugal.

A mais recente evolução na organização nacional deu-se em agosto de 2015, quando um Despacho conjunto dos Ministros de Estado e das Finanças, dos Negócios Estrangeiros, da Economia e do Ambiente, Ordenamento do Território e Energia ${ }^{52}$ manifesta a intenção de vir a imprimir «uma nova dinâmica» ao funcionamento da Comissão Nacional.

Assim, além de alterar a designação da Comissão para «Comité Nacional do Programa Man and the Biosphere» ou «Comité Nacional MaB», altera ainda a sua composição e competências.

Na composição, é de realçar a participação de um representante de cada uma das oito reservas portuguesas. Eis a composição atual:

a) Um representante do Instituto da Conservação da Natureza e das Florestas, I. P. (ICNF, I. P.), que preside;

b) Um representante de cada uma das reservas da biosfera designadas em Portugal Continental e nas Regiões Autónomas da Madeira e dos Açores;

c) Um representante do Instituto do Turismo de Portugal, I. P. (Turismo de Portugal, I. P.);

d) Um representante do Conselho Nacional do Ambiente e do Desenvolvimento Sustentável (CNADS);

e) Um representante da CNU

Quanto às atribuições, não divergem muito das que detinha sob a anterior designação, desde 2006, embora seja expectável a concretização de uma maior participação de atores sociais nas atividades de gestão das reservas, na medida em que cabe ao Comité $\mathrm{MaB}$ «promover, em colaboração com a CNU, a interligação entre as diversas entidades, públicas ou privadas, relacionadas com o Programa MaB».

Além desta, as restantes atribuições são:

- Coordenar, em colaboração com a Comissão Nacional da UNESCO (CNU), as atividades do Programa MaB em Portugal;

- Promover o conceito de reserva da biosfera;

- Assegurar a representação nacional nas reuniões do Comité Científico do Conselho de Coordenação Internacional do Programa MaB e nas reuniões do Bureau do $\mathrm{MaB}$;

\footnotetext{
internacionais, nomeadamente quando relacionados com 0 Programa MaB;

f) Pronunciar-se, quando solicitado, no processo de aplicação nacional das convenções internacionais, designadamente a Convenção de Ramsar, a Convenção do Património Mundial, Cultural e Natural e as convenções sobre a diversidade biológica e sobre o combate à desertificação; g) Desenvolver quaisquer outras actividades que contribuam para promover os objectivos do Programa MaB em Portugal.

${ }^{52}$ Respetivamente, subscrevem o diploma Hélder Manuel Gomes dos Reis (Secretário de Estado Adjunto e do Orçamento, em representação da Ministra); Rui Manuel Parente Chancerelle de Machete; António de Magalhães Pires de Lima e Jorge Manuel Lopes Moreira da Silva.
} 
- Pronunciar -se, quando solicitado, nos processos de participação de Portugal noutros programas internacionais na área da biodiversidade, quando relacionados com o Programa MaB;

- Analisar, em colaboração com a CNU, as candidaturas nacionais para a classificação de novas reservas da biosfera;

- Divulgar as bolsas e prémios promovidos pelo Programa MaB, nomeadamente o «MaB Young Scientists», o «Prémio Sultão Qaboos» e o «Prémio Michel Matisse», receber as candidaturas nacionais e remetê-las à CNU;

- Desenvolver quaisquer outras atividades que contribuam para a promoção em Portugal dos objetivos do Programa MaB.

\section{Conclusão}

Depois de anos de marasmo, o contributo de Portugal para a rede mundial de reservas de biosfera começa lentamente a fazer-se sentir. A evolução que se espera que venha a acontecer no futuro permitirá passar de uma classificação simbólica, da qual pouco mais se esperava do que alguns dividendos turísticos, para uma classificação real, em que o «rótulo Unesco» será uma distinção merecida de um espaço privilegiado, por estar em perfeita sintonia com o objetivo último da rede Unesco: mostrar que, com o envolvimento de todos é possível conciliar ambiente com bem-estar, conservação da natureza com qualidade de vida. Numa palavra, mostrar que que a sustentabilidade é possível. 